\title{
ARTICLE
}

\section{Activation and splitting of carbon dioxide on the surface of an inorganic electride material}

Yoshitake Toda1, Hiroyuki Hirayama², Navaratnarajah Kuganathan ${ }^{3}$, Antonio Torrisi ${ }^{3}$, Peter V. Sushko ${ }^{3}$ \& Hideo Hosono ${ }^{1,4}$

Activation of carbon dioxide is the most important step in its conversion into valuable chemicals. Surfaces of stable oxide with a low work function may be promising for this purpose. Here we report that the surfaces of the inorganic electride $\left[\mathrm{Ca}_{24} \mathrm{Al}_{28} \mathrm{O}_{64}\right]^{4+}\left(e^{-}\right)_{4}$ activate and split carbon dioxide at room temperature. This behaviour is attributed to a high concentration of localized electrons in the near-surface region and a corrugation of the surface that can trap oxygen atoms and strained carbon monoxide and carbon dioxide molecules. The $\left[\mathrm{Ca}_{24} \mathrm{Al}_{28} \mathrm{O}_{64}\right]^{4+}\left(e^{-}\right)_{4}$ surface exposed to carbon dioxide is studied using temperature-programmed desorption, and spectroscopic methods. The results of these measurements, corroborated with ab initio simulations, show that both carbon monoxide and carbon dioxide adsorb on the $\left[\mathrm{Ca}_{24} \mathrm{Al}_{28} \mathrm{O}_{64}\right]^{4+}\left(e^{-}\right)_{4}$ surface at $\mathrm{RT}$ and above and adopt unusual configurations that result in desorption of molecular carbon monoxide and atomic oxygen upon heating.

\footnotetext{
${ }^{1}$ Frontier Research Center, Tokyo Institute of Technology, 4259 Nagatsuta, Midori-ku, Yokohama 226-8503, Japan. ${ }^{2}$ Department of Materials Science and Engineering, Tokyo Institute of Technology, 4259 Nagatsuta, Midori-ku, Yokohama 226-8503, Japan. ${ }^{3}$ Department of Physics and Astronomy and the London Centre for Nanotechnology, University College London, Gower Street, London WC1E 6BT, UK. ${ }^{4}$ Materials Research Center for Element Strategy, Tokyo Institute of Technology, 4259 Nagatsuta, Midori-ku, Yokohama 226-8503, Japan. Correspondence and requests for materials should be addressed to H.H. (email: hosono@msl.titech.ac.jp).
} 
E fficient and inexpensive conversion of $\mathrm{CO}_{2}$ into valuable chemicals would simultaneously contribute to reducing $\mathrm{CO}_{2}$ emission into the atmosphere and lessen the dependence of society on fossil fuels ${ }^{1,2}$. Activation and splitting of the $\mathrm{CO}_{2}$ molecule are the most important steps in this process. However, because $\mathrm{CO}_{2}$ is nonpolar and has two double bonds, its activation requires high temperature/pressure conditions and/or active reductants, such as hydrogen. Alternatively, $\mathrm{CO}_{2}$ can be activated under ambient conditions with the help of a solidstate catalyst, the role of which is to adsorb $\mathrm{CO}_{2}$ molecules and facilitate electron transfer to them ${ }^{3}$. Solid-state bases, such as alkaline earth metals and alkaline earth metal oxides, are known to be $\mathrm{CO}_{2}$ sorbants, and numerous studies on the formation of 'bent' $\mathrm{CO}_{2}^{\delta-}$ configurations on their surfaces have been reported ${ }^{4-9}$. However, formation of these $\mathrm{CO}_{2}^{\delta-}$ species alone does not lead to $\mathrm{CO}_{2}$ splitting. Surfaces of transition and $s p$ metals, either on their own, such as $\mathrm{Cu}^{10}$, or doped with alkali metal atoms so as to reduce their work function, can activate $\mathrm{CO}_{2}$ and generate $\mathrm{CO}$ through decomposition of $\mathrm{CO}_{2}^{\delta-}$ and/or $\mathrm{CO}_{3}^{\delta-}$ intermediates ${ }^{11-13}$. However, this approach is impractical for industrial applications because it requires a combination of low temperatures, delicate surface control and/or expensive metals. Thus, there is a need for new materials, which offer both high chemical stability and high ability to facilitate electron transfer to $\mathrm{CO}_{2}$ and induce its dissociation.

$\left[\mathrm{Ca}_{24} \mathrm{Al}_{28} \mathrm{O}_{64}\right]^{4+}\left(e^{-}\right)_{4}$, or C12A7: $e^{-}$for brevity ${ }^{14-16}$, is an electride ${ }^{17-19}$, that is, a material in which electrons serve as anions. As shown in Fig. 1, the crystal framework of C12A7: $e^{-}$is formed by a three-dimensional network of interconnected cages with the inner diameter of $\sim 0.4 \mathrm{~nm}$. The cages each bear a positive charge of $+1 / 3$, which is compensated by extraframework electrons-'anionic electrons'-clathrated in them. The local atomic environment of these anionic electrons, in particular the arrangement of the nearest six $\mathrm{Ca}^{2+}$ ions, is similar to that of an $\mathrm{F}^{+}$-centre in a $\mathrm{CaO}$ crystal, that is, an electron trapped at the site of an $\mathrm{O}^{2-}$ vacancy. The concentrations of the cages $\left(\sim 6 \times 10^{21} \mathrm{~cm}^{-3}\right)$ and of the anionic electrons $\left(\sim 2 \times 10^{21}\right.$ $\mathrm{cm}^{-3}$ ) in C12A7: $e^{-}$are large enough to form a partially occupied band rather than a set of discrete energy levels. As the average cage diameter is $\sim 1.5$ times that of the oxygen vacancy in $\mathrm{CaO}$ and the cage wall charge is lower than that provided by the $\mathrm{F}^{+}$-centre environment, the Madelung potential at the cage centre is rather small. This explains why the work function of $\mathrm{C} 12 \mathrm{~A} 7: e^{-}$is only $2.4 \mathrm{eV}$, which is close to that of potassium

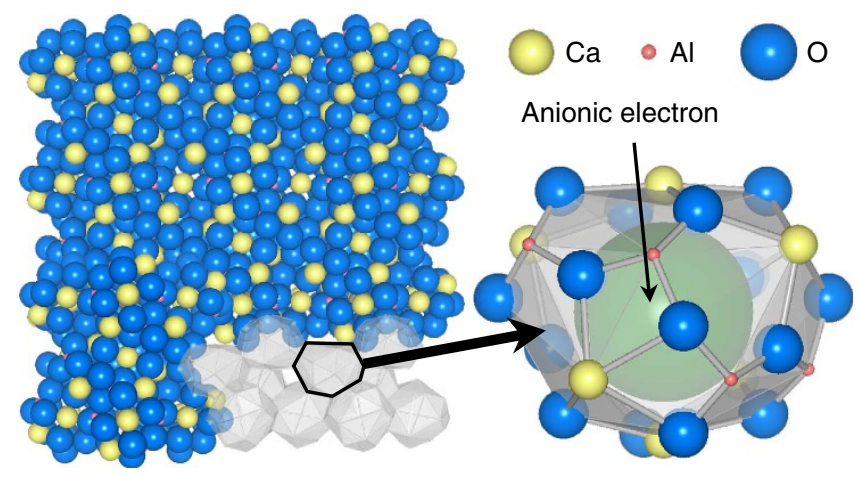

Figure 1 | Schematic illustration of the (100) surface of C12A7:e ${ }^{-}$. The model draws upon STM studies of C12A7: $e^{-22}$. Yellow, red and blue spheres represent $\mathrm{Ca}, \mathrm{Al}$ and $\mathrm{O}$ atoms, respectively. The lower right portion of the model is drawn without atom spheres, and the white polygons represent the interior spaces of the cages. The figure on the right shows magnification of the cages and the clathrated anionic electron (green sphere). metal $^{20}$. Furthermore, the anionic electrons confined to cages act as chemically active centres facilitating adsorption of molecular contaminants, such as $\mathrm{H}_{2} \mathrm{O}, \mathrm{O}_{2}$ and $\mathrm{CO}_{2}$, at the surface. However, the small size of the openings between the cages does not allow for these species to penetrate through the cage wall under ambient conditions. Thus, C12A7: $e^{-}$is chemically inert despite its work function being comparable to that of highly reactive metals, such as alkali metals.

In this article, we report that $\mathrm{CO}_{2}$ adsorbed on the $\mathrm{C} 12 \mathrm{~A} 7: e^{-}$ surface dissociates into $\mathrm{CO}$ and atomic oxygen at room temperature (RT). Temperature-programmed desorption (TPD) measurements were carried out to estimate the capacity of the C12A7: $e^{-}$surface to adsorb $\mathrm{CO}_{2}$. The adsorbed $\mathrm{CO}_{2}$ and the products of its decomposition were analysed by photoelectron spectroscopy (PES) and Fourier transform infrared reflection absorption spectroscopy (FTIR-RAS). These experimental data, together with $a b$ initio simulations, allowed us to establish the atomic-scale mechanism for adsorption and dissociation of $\mathrm{CO}_{2}$ on the $\mathrm{C} 12 \mathrm{~A} 7: e^{-}$surface.

\section{Results}

$\mathrm{CO}$ and $\mathrm{CO}_{2}$ species on the surface of $\mathrm{C12A7:} e^{-}$. To investigate whether $\mathrm{CO}_{2}$ is adsorbed on the $\mathrm{C} 12 \mathrm{~A} 7: e^{-}$surface, we compared the TPD spectra for several surfaces exposed to the same amount of $\mathrm{C}^{18} \mathrm{O}_{2}\left(95 \%{ }^{18} \mathrm{O}\right.$ isotopic purity Isotech gas was used to eliminate the contribution of residual gases, such as $\mathrm{C}^{16} \mathrm{O}_{2}$ and $\mathrm{C}^{16} \mathrm{O}$ ). The data in Fig. 2a demonstrate that the TPD yield for $\mathrm{C} 12 \mathrm{~A} 7: e^{-}$is noticeably larger than that for other oxide surfaces. Figure $2 \mathrm{~b}$ shows that adsorption of $\mathrm{CO}_{2}$ reaches saturation at much lower exposure $(\sim 2 \mathrm{~L})$ than in the case for $\mathrm{H}_{2}, \mathrm{~N}_{2}, \mathrm{O}_{2}$ and $\mathrm{CO}$. Thus, these results demonstrate that $\mathrm{C} 12 \mathrm{~A} 7: e^{-}$adsorbs $\mathrm{CO}_{2}$ quickly and in large quantities compared with other gaseous species. We estimate the amount of adsorbed $\mathrm{CO}_{2}$ to be at least $10^{13} \mathrm{~cm}^{-2}$, which agrees well with the density of anionic electrons at the $\mathrm{C} 12 \mathrm{~A} 7: e^{-}$surface.

TPD spectra obtained after saturation exposures of $\mathrm{CO}_{2}$ at RT are shown in Fig. 2c. Analysis of the spectral composition with $\mathrm{m} / z$ values up to 50 reveals that $\mathrm{CO}_{2}, \mathrm{CO}$ and $\mathrm{O}$ were the dominant desorption products; no evidence for the presence of other species, for example, $\mathrm{O}_{2}$ and derivatives of $\mathrm{CO}_{2}$, such as formic acid and formaldehyde ${ }^{21}$, was found. The intensities of the $\mathrm{CO}_{2}$ and $\mathrm{CO}$ TPD signatures were calibrated using the corresponding sensitivity factors. The $\mathrm{O}$-atom TPD signal was calibrated using the sensitivity factor for $\mathrm{CO}_{2}$ and distinguished from the background $\mathrm{H}_{2} \mathrm{O}$ (the partial pressure of $\mathrm{H}_{2} \mathrm{O}$ in our apparatus is $<1 \times 10^{-10} \mathrm{~Pa}$ ). All spectra were broad and covered the temperature range from $\mathrm{RT}$ to $1,273 \mathrm{~K}$, indicating the presence of several types of binding sites. In particular, the $\mathrm{CO}_{2}, \mathrm{CO}$ and $\mathrm{O}$ species started to desorb at about 350, 400 and $700 \mathrm{~K}$, respectively. Desorption of $\mathrm{CO}_{2}$ was completed at about $1,200 \mathrm{~K}$. In contrast, the yield of both $\mathrm{CO}$ and $\mathrm{O}$ drastically increased at temperatures $>1,200 \mathrm{~K}$, and neither $\mathrm{CO}$ nor $\mathrm{O}$ was completely desorbed at $1,273 \mathrm{~K}$. These data clearly demonstrate that, unlike in other oxides, the main desorption product here is $\mathrm{CO}$.

We note that the shape of the CO TPD spectrum (Fig. 2c) differs remarkably from that for $\mathrm{CO}_{2}$, and their yields differ by a factor of three. This observation rules out the possibility that the detected $\mathrm{CO}$ is produced by cracking desorbed $\mathrm{CO}_{2}$ in the ionizer of the mass spectrometer. Hence, we conclude that the $\mathrm{CO}$ originates from the $\mathrm{CO}_{2}$ pre-adsorbed at the $\mathrm{C} 12 \mathrm{~A} 7: e^{-}$surface. In contrast, in the case of $\mathrm{C} 12 \mathrm{~A} 7: \mathrm{O}^{2-}$, which contains no anionic electrons, the amount of desorbed $\mathrm{CO}_{2}$ is $<50 \%$ of that detected for the $\mathrm{C} 12 \mathrm{~A} 7: e^{-}$, the TPD CO spectrum has a profile similar to that for $\mathrm{CO}_{2}$, and the magnification ratio of the $\mathrm{CO}$ spectrum is 
close to the pattern coefficient for fragmenting $\mathrm{CO}_{2}$ by the ionizer of MSQ-400 (see Methods). Finally, we observed that the TPD yields and spectral profiles did not change after more than 20 cycles of $\mathrm{CO}_{2}$ exposure followed by TPD measurements up to $\sim 1,273 \mathrm{~K}$. However, if the TPD procedure was terminated at $1,000 \mathrm{~K}$, the CO yield decreased gradually from one TPD cycle to another. This result suggests that the surface sites responsible for $\mathrm{CO}$ generation do not fully recover at $\leq 1,000 \mathrm{~K}$, which points to the crucial role of the oxygen-deficient, that is, electron-rich C12A7 surface.

According to our calculations (see Methods for details), there are five types of $\mathrm{CO}_{2}$ adsorbed on the $\mathrm{C} 12 \mathrm{~A} 7: e^{-}$surface. Figure 3 details their geometrical configurations and adsorption energies as calculated using the Perdew, Burke and Ernzerhof (PBE) density functional. Although the surface of $\mathrm{C} 12 \mathrm{~A} 7: e^{-}$preserves the complex cage structure characteristic of bulk C12A7, it becomes partially disordered ${ }^{22}$. Therefore, each type of adsorbed $\mathrm{CO}_{2}$ is characterized by a range of adsorption energies. The same applies to the reaction activation energies. The thermodynamically least stable species are physisorbed $\mathrm{CO}_{2}$ (see Supplementary Note 1) having the calculated binding energy of about $0.3 \mathrm{eV}$ (at least $\sim 0.5 \mathrm{eV}$ if the dispersion interaction is taken into account). In this case, the molecule binds to either a surface $\mathrm{Ca}$ or an $\mathrm{Al}$ atom and retains its linear configuration, as shown in Fig. 3 a.
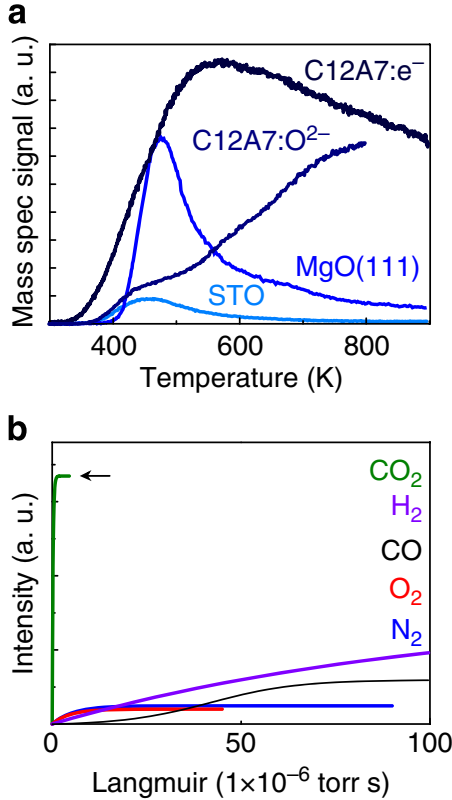

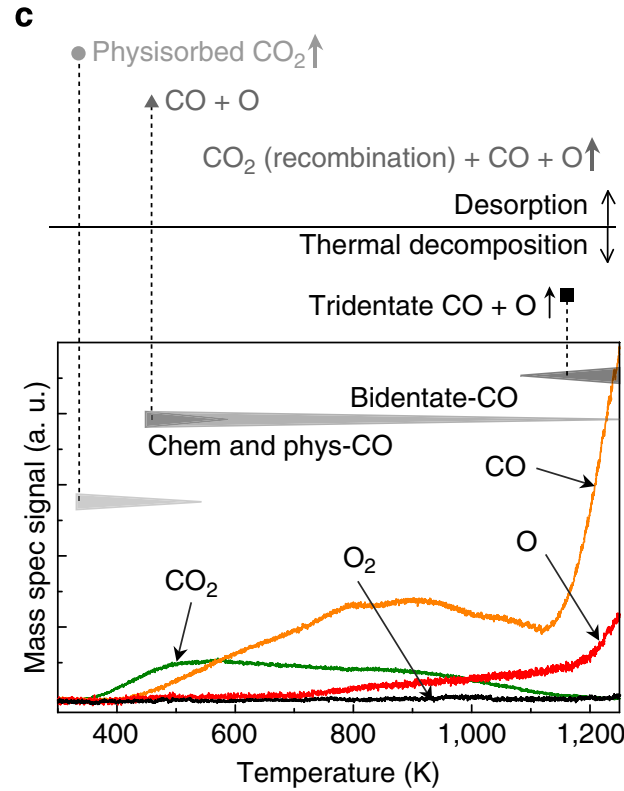

Figure 2 | TPD curves. (a) $\mathrm{CO}_{2}\left(\mathrm{C}^{18} \mathrm{O}_{2}\right)$ TPD curves of $\mathrm{C} 12 \mathrm{A7} 7: \mathrm{e}^{-}, \mathrm{C} 12 \mathrm{A7} 7: \mathrm{O}^{2-}$ (film), MgO (111) (film) and $\mathrm{SrTiO}_{3}: \mathrm{Nb}$ after $1 \mathrm{~L}$ of $\mathrm{CO}_{2}$ exposure. (b) Saturation curves of $\mathrm{CO}_{2}, \mathrm{H}_{2}, \mathrm{~N}_{2}, \mathrm{O}_{2}$ and $\mathrm{CO}$ adsorption on the C12A7: $e^{-}$surface. The curves were derived from the change in the degree of vacuum during TPD and the integrated areas under the TPD curves. (c) TPD curves of all desorption products from the $\mathrm{C} 12 \mathrm{~A} 7: \mathrm{e}^{-}$surface after $2 \mathrm{~L}$ of exposure to $\mathrm{CO}_{2}$ at $\mathrm{RT}$ with the proposed $\mathrm{CO}_{2}$ desorption and decomposition sequence. The intensities of the curves were calibrated by sensitivity factors. The heating rate was $0.5 \mathrm{Ks}^{-1}$.

a

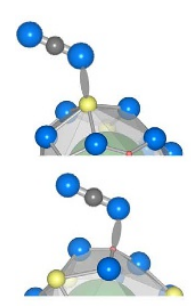

b

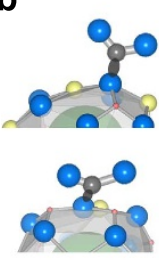

C

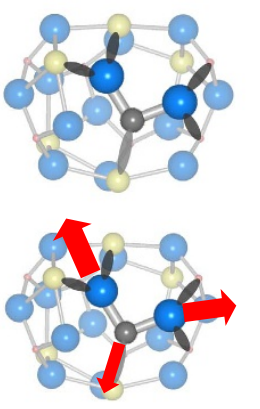

$\mathrm{Ca} \odot \mathrm{Al}$

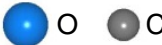

d

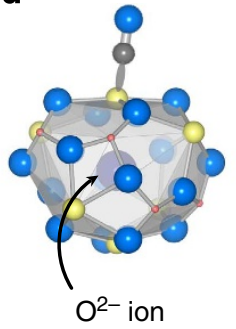

e

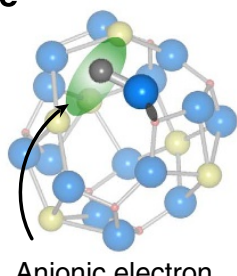

Energy $(\mathrm{eV})$

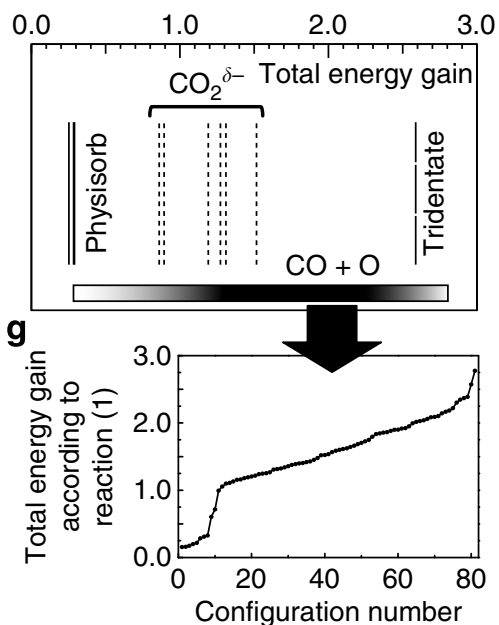

Figure 3 | Configurations and adsorption energies of $\mathbf{C O}_{2}$ molecules adsorbed on C12A7: $\mathbf{e}^{-}$. (a-e) Geometrical configurations of a $\mathrm{CO}_{2}$ molecule adsorbed on C12A7: $e^{-}$surface: (a) physisorbed configuration, (b) $\mathrm{CO}_{2}^{\delta-}$, (c) tridentate $\mathrm{CO}_{2}$, (d, e) dissociation into $\mathrm{O}^{2-}$ and $\mathrm{CO}$ species. (f) Adsorption energy ranges for the five types of $\mathrm{CO}_{2}$ configurations: physisorbed $\mathrm{CO}_{2}$, bent $\mathrm{CO}_{2}^{\delta-}$, dissociated (two types) and tridentate. (g) Energy gain according to reaction (1) for all considered configurations of the resulting $\mathrm{CO}$, including the bidentate $\mathrm{CO}$ and $\mathrm{O}^{2-}$. 
In more stable configurations, the $\mathrm{C}$ atom of $\mathrm{CO}_{2}$ binds to a surface oxide ion, and the two $\mathrm{C}=\mathrm{O}$ bonds are oriented away from the surface (see Fig. 3b). This configuration is often referred to as bent $\mathrm{CO}_{2}^{\delta-}$, where $\delta$ is the amount of electron charge transferred from the $\mathrm{C} 12 \mathrm{~A} 7: e^{-}$to the adsorbed, no longer linear, $\mathrm{CO}_{2}$ molecule. The calculated adsorption energies for this configuration are $0.8-1.5 \mathrm{eV}(1.2-2.3 \mathrm{eV}$ in B3LYP), and the values of $\delta$ are $0.6-0.7$ depending on the local atomic structure of the adsorption site. The ranges of $\mathrm{C}-\mathrm{O}$ distances and $\mathrm{O}-\mathrm{C}-\mathrm{O}$ angles are $1.24-1.31 \AA$ and $127-131^{\circ}$, respectively.

The tridentate configuration, a special case of a bent and charged ${ }^{23}$ adsorbed $\mathrm{CO}_{2}$ molecule, is shown in Fig. $3 \mathrm{c}$. Here the oxygen atoms bind to cations of a partially broken cage such that the molecule becomes part of the cage wall. The $\mathrm{C}-\mathrm{O}$ distance elongates to $1.30 \AA$ and the $\mathrm{O}-\mathrm{C}-\mathrm{O}$ angle decreases to $\sim 117^{\circ}$ so that the $\mathrm{C}$ atom faces one of the under-coordinated $\mathrm{Ca}^{2+}$ ions. According to a Mulliken population analysis, over $-1.6|e|$ is transferred from the $\mathrm{C} 12 \mathrm{~A} 7: e^{-}$to the molecule and is shared between the oxygen atoms and the central $\mathrm{C}$ atom, which forms a $\mathrm{C}-\left(e^{-}\right)-\mathrm{Ca}^{2+}$ bond with a cage wall ion. The calculated adsorption energy for this configuration is $2.6 \mathrm{eV}(4.5 \mathrm{eV}$ in B3LYP) (see Supplementary Note 2).

In addition, gas-phase $\mathrm{CO}_{2}$ can be adsorbed via dissociation into $\mathrm{O}$ and $\mathrm{CO}$ species:

$$
\begin{aligned}
& \mathrm{CO}_{2}(\text { gas })+(2+k) e^{-}(\text {cage })+\mathrm{M}^{\mathrm{n}}+(\mathrm{LC}) \\
& \quad \rightarrow \mathrm{CO}^{\mathrm{k}-}(\text { surface })+0 e^{-}(\text {cage })+\mathrm{O}^{2-} \mathrm{M}^{\mathrm{n}+}(\mathrm{LC}),
\end{aligned}
$$

where $0<k<2$. In this reaction, two anionic electrons are transferred from the near-surface region to the $\mathrm{O}$ atom, which becomes an $\mathrm{O}^{2-}$ ion and occupies a site near the lowcoordinated (LC) surface cations $\left(\mathrm{M}^{\mathrm{n}}+\right)$. The binding energy of the $\mathrm{CO}^{k-}$ and the value of $k$ depend on the local surface structure and the availability of anionic electrons. In particular, neutral $\mathrm{CO}$ molecules are physisorbed at the $\mathrm{Ca}^{2+}$ ions with adsorption energies of up to $0.3 \mathrm{eV}$ (Fig. $3 \mathrm{~d}$ ) and are chemisorbed forming $\mathrm{OC}-\mathrm{Al}$ configurations with binding energies of up to $0.5 \mathrm{eV}$ ( $>0.75 \mathrm{eV}$ with the dispersion interaction) due to $\sim 0.3 e$ transfer from $\mathrm{C} 12 \mathrm{~A} 7: e^{-}$to the $p$-orbitals of the carbon atom. Alternatively, CO molecules bind between two or more LC surface cations forming 'bidentate CO' configurations (Fig. 3e) with binding energies in the range of $0.1-1.1 \mathrm{eV}(0.7-2.2 \mathrm{eV}$ in B3LYP). According to a Mulliken population analysis, as much as $-1.5|e|$ is transferred from the surface to the $\mathrm{CO}$ molecules. Hence, they are regarded as chemisorbed species, even though the binding energies can be small, and are represented as $\mathrm{M}_{1}^{\mathrm{n}}{ }_{-}-$ $\left(e^{-}\right)-\mathrm{CO}^{-}-\mathrm{M}_{2}^{\mathrm{m}+}$, where $\mathrm{M}_{1}^{\mathrm{n}+}$ and $\mathrm{M}_{2}^{\mathrm{m}+}$ are surface cations. The C-O bonds elongate to 1.27-1.34 $\AA$ depending on the details of the local atomic structure (see Supplementary Figs S1 and S2).

We emphasize that the tridentate and dissociated $\mathrm{O}+\mathrm{CO}$ configurations of $\mathrm{CO}_{2}$ exist because of the unusual features of the C12A7: $e^{-}$surface: (i) the partially broken cages that accommodate $\mathrm{O}$ atoms and the entire $\mathrm{CO}$ and $\mathrm{CO}_{2}$ molecules and (ii) the high concentration and low binding energy of the anionic electrons, which stabilize the adsorbed $\mathrm{O}, \mathrm{CO}$ and $\mathrm{CO}_{2}$. The adsorption energies calculated using the PBE functional increase by at least $0.15-0.2 \mathrm{eV}$ when the dispersion interaction correction is applied ${ }^{24}$.

$\mathrm{CO}_{2}$ decomposition. To test the feasibility of $\mathrm{CO}_{2} \rightarrow \mathrm{CO}+\mathrm{O}$ splitting (see reaction (1)), we considered several pathways, in which the resulting $\mathrm{CO}$ is physisorbed, and calculated the corresponding activation energies. For the physisorbed $\mathrm{CO}_{2}$, the lowest activation energy found is $\sim 1 \mathrm{eV}$. Alternatively, the $\mathrm{CO}_{2}$ pre-adsorbed at the surface in the bent $\mathrm{CO}_{2}^{\delta-}$ configuration is split with an activation energy of $\sim 1.5 \mathrm{eV}$. In all cases, one of the
$\mathrm{C}=\mathrm{O}$ bonds ruptures, and the oxygen atom traps two subsurface electrons and binds to $\mathrm{LC}$ cations as an $\mathrm{O}^{2-}$ ion. For the pathways that we have considered, this process is also accompanied by displacement of another surface $\mathrm{O}^{2-}$ ion into subsurface extraframework sites via the interstitialcy diffusion mechanism that was found to dominate $\mathrm{O}^{2-}$ ion diffusion in bulk $\mathrm{C} 12 \mathrm{~A} 7: \mathrm{O}^{2-}$ (refs 25-27).

The overall energy balance for reaction (1) is calculated as the sum of two contributions: (i) $\mathrm{CO}_{2} \rightarrow \mathrm{O}+\mathrm{CO}$ splitting in the gas phase followed by trapping the $\mathrm{O}$ atom at the surface according to $\mathrm{O}+2 e^{-} \rightarrow \mathrm{O}^{2-}$ and (ii) adsorption of the $\mathrm{CO}$ molecule. The calculated energy gain for the former contribution is up to $1.7 \mathrm{eV}$ (3.5 eV in B3LYP). Taking into account the adsorption energy for the bidentate $\mathrm{CO}$, the total energy gain due to the dissociative $\mathrm{CO}_{2}$ adsorption can be up to $2.8 \mathrm{eV}$ ( $5.7 \mathrm{eV}$ in B3LYP). This wide range of calculated $\mathrm{CO}_{2}$ and $\mathrm{CO}$ adsorption energies correlates well with the broad multiple-peak TPD spectra.

Infrared spectroscopy. Figure 4 shows FTIR-RAS spectra for a clean surface of $\mathrm{C} 12 \mathrm{~A} 7: e^{-}$and one exposed to $\mathrm{CO}_{2}$ gas at RT. Non-negligible infrared bands appear in the ranges of $1,200-1,280$ and $2,300-2,400 \mathrm{~cm}^{-1}$. The intensity of the $1,200-1,280 \mathrm{~cm}^{-1}$ band saturates after $2 \mathrm{~L}$ of $\mathrm{CO}_{2}$ exposure, which is in good agreement with the TPD and PES (shown below) results, suggesting that this band originates from the adsorbed $\mathrm{CO}_{2}$. This band did not disappear until the sample temperature was raised $>1,273 \mathrm{~K}$. The $2,300-2,400 \mathrm{~cm}^{-1}$ band (Fig. 4b) overlaps with the background gaseous $\mathrm{CO}_{2}$ band (BG). The intensity of BG randomly changed by the minute. Therefore, we evaluated the qualitative difference between spectra for the clean and one exposed to $2 \mathrm{~L}$ of $\mathrm{CO}_{2}$, which arbitrarily uniformed by the infrared band centred at $2,361 \mathrm{~cm}^{-1}$ derived from gaseous $\mathrm{CO}_{2}$. Here, the ' $2 \mathrm{~L}$ ' spectrum is expanded to normalize its intensity with the 'clean' spectrum. This procedure puts the maximum of the infrared band due to adsorbed $\mathrm{CO}_{2}$ at $2,345 \mathrm{~cm}^{-1}$.

To assign these infrared features, we calculated the vibrational frequencies and infrared intensities for all types of adsorbed $\mathrm{CO}_{2}$. The physisorbed near-linear $\mathrm{CO}_{2}$ was found to be the likely origin of the $2,300-2,400 \mathrm{~cm}^{-1}$ infrared band, as it has an infrared-active mode at $\sim 2,360 \mathrm{~cm}^{-1}$ (asymmetric stretching) and an infraredinactive mode at $1,300-1,315 \mathrm{~cm}^{-1}$ (symmetric stretching). In the $\mathrm{CO}_{2}^{\delta-}$ configurations, the asymmetric and symmetric stretching modes transform into 1,660-1,680 and $1,210-1,260 \mathrm{~cm}^{-1}$ bands, respectively. Both bands are infrared-active and have comparable intensities. As the experimental data show no indication of infrared absorption in the $1,660-1,680 \mathrm{~cm}^{-1}$ range, we conclude that the $\mathrm{CO}_{2}^{\delta-}$ configurations do not form in C12A7: $e^{-}$at RT, which is consistent with the calculated formation energies of $\mathrm{CO}_{2}^{\delta-}$ being smaller than those of the tridentate and dissociated $\mathrm{O}+\mathrm{CO}$ configurations. However, this does not preclude the formation of transient $\mathrm{CO}_{2}^{\delta-}$ species as, for example, precursors to $\mathrm{O}+\mathrm{CO}$ configurations. Importantly, because the $\mathrm{CO}_{2}^{\delta-}$ species, tridentate and $\mathrm{O}+\mathrm{CO}$ configurations are stabilized by electron transfer from $\mathrm{C} 12 \mathrm{~A} 7: e^{-}$, the concentration of these species is limited by the availability of such electrons in the near-surface region.

In the case of the tridentate configuration (Fig. 3c), the two most active modes are similar to the asymmetric and symmetric vibrations of a water molecule and have calculated frequencies of $\sim 1,310$ and $\sim 1,210 \mathrm{~cm}^{-1}$, respectively, and an intensity ratio of approximately $4: 1$. As shown in the lower panel of Fig. $3 \mathrm{c}$, the tridentate $\mathrm{CO}_{2}$ molecule is effectively pulled apart by the oxygen atoms binding to two $\mathrm{Ca}^{2+}$ ions on one side and one $\mathrm{Al}^{3+}$ on the other and by the central $\mathrm{C}$ atom forming a $\mathrm{C}-\left(e^{-}\right)-\mathrm{Ca}^{2+}$ bond with the cage wall. The calculated frequencies agree well 
a

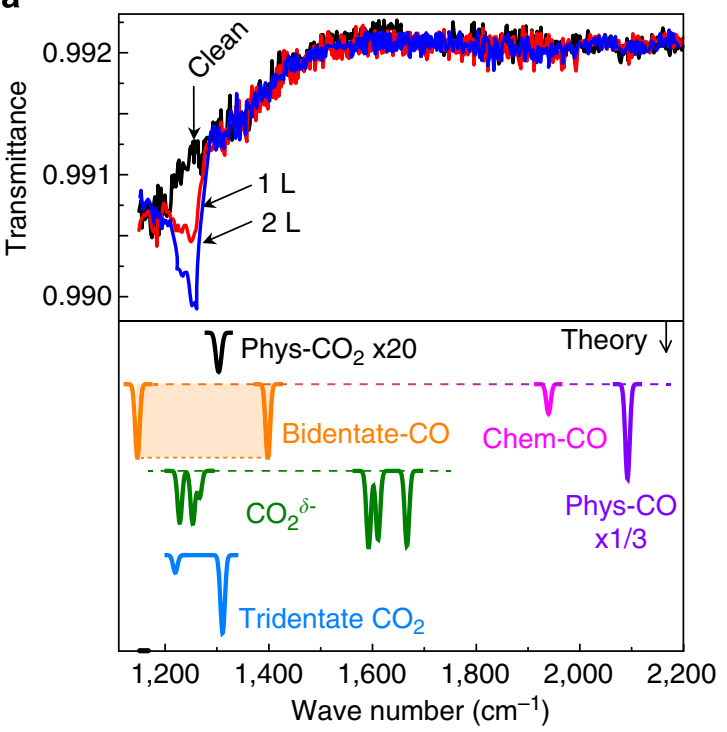

b

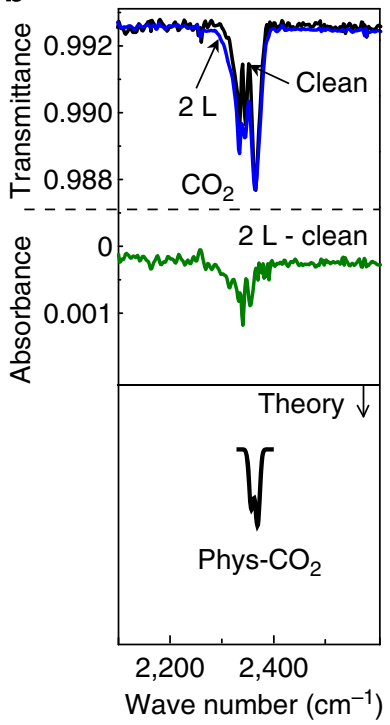

Figure 4 | FTIR-RAS spectra and wave number position of possible surface species. (a,b) FTIR-RAS spectra of the C12A7: $e^{-}$surface after various (clean, 1 and $2 \mathrm{~L}$ ) levels of exposure to $\mathrm{CO}_{2}$ at RT. (b) Clean and $2 \mathrm{~L}$ spectra near the background gaseous $\mathrm{CO}_{2}$ band and difference spectrum of them.

Table 1 | Possible species adsorbed on C12A7: $e^{-}$surface and their experimental observation.

\begin{tabular}{|c|c|c|c|c|c|c|}
\hline \multirow{2}{*}{\multicolumn{2}{|c|}{ Possible species (theory) }} & \multirow[t]{2}{*}{ Physisorbed $\mathrm{CO}_{2}$} & \multirow[t]{2}{*}{$\operatorname{co}_{2}^{\delta-}$} & \multicolumn{2}{|c|}{$\mathrm{CO}+\mathrm{O}$} & \multirow{2}{*}{$\begin{array}{c}\text { Tridentate } \mathrm{CO}_{2} \\
\text { (surface and bulk }\end{array}$} \\
\hline & & & & $\begin{array}{l}\text { Chemisorbed/ } \\
\text { physisorbed CO }\end{array}$ & $\overline{\text { Bidentate CO }}$ & \\
\hline \multirow[t]{2}{*}{ Experiment } & FTIR-RAS & Yes & No & Possible & \multicolumn{2}{|c|}{ Yes (overlap) } \\
\hline & XPS & Yes & Possible & Possible & Yes & Yes \\
\hline
\end{tabular}

with the experimental data, which explains the existence of two bands in the $1,200-1,300 \mathrm{~cm}^{-1}$ region with the lower-energy band having a lower intensity, and are consistent with the calculated high thermodynamic stability of the tridentate $\mathrm{CO}_{2}$.

Finally, for the $\mathrm{O}+\mathrm{CO}$ configurations, the calculated stretching frequencies for the bidentate $\mathrm{CO}$ are in the range of $1,150-$ $1,410 \mathrm{~cm}^{-1}$. Generalized gradient approximation (GGA) functionals are known to overdelocalize electronic defect states. In the case of $\mathrm{M}_{1}^{\mathrm{n}}+-\left(e^{-}\right)-\mathrm{CO}^{-}-\mathrm{M}_{2}^{\mathrm{m}}+$ configurations, this would result in an underestimated $\mathrm{M}_{1}^{\mathrm{n}}{ }_{-}\left(e^{-}\right)-\mathrm{C}$ binding and, consequently, overestimated CO stretching frequency. Therefore, we conclude that the calculated infrared frequencies of the bidentate $\mathrm{CO}$ are consistent with the experimentally observed infrared absorption band at $1,200-1,300 \mathrm{~cm}^{-1}$. The infrared signatures of the chemisorbed and physisorbed monodentate $\mathrm{CO}$ are at 1,900 and $2,100 \mathrm{~cm}^{-1}$, respectively. Although the FTIR-RAS spectra show no noticeable infrared absorption in this frequency range, this does not preclude the existence of chemisorbed CO. Indeed, transfer of a fraction of an electron to the $\mathrm{C}$ atom of the adsorbed $\mathrm{CO}$ reduces its dipole moment and may result in infrared-silent CO species. Thus, comparison of these theoretical results with experimental infrared spectra suggests that tridentate $\mathrm{CO}_{2}$, bidentate $\mathrm{CO}$, physisorbed $\mathrm{CO}_{2}$ and, possibly, chemisorbed monodentate CO species co-exist at the C12A7: $e^{-}$surface (see Table 1). We note that FTIR-RAS data alone are not sufficient to resolve between the tridentate $\mathrm{CO}_{2}$ and bidentate $\mathrm{CO}$ configurations; hence, these results must be accompanied by other spectroscopic measurements.

Photoelectron spectroscopy. Figure 5a shows ultraviolet photoelectron spectroscopy (UPS) spectra for a clean C12A7: $e^{-}$ surface and a surface exposed to $\mathrm{CO}_{2}(1$ and $2 \mathrm{~L})$ at RT. The clean surface shows a well-defined Fermi edge (inset in Fig. 5a) firmly attributed to anionic electrons. The spectrum taken after $1 \mathrm{~L}$ of $\mathrm{CO}_{2}$ exposure exhibits two additional peaks at binding energies of 9.2 and $11.5 \mathrm{eV}$. After dosing the surface with $2 \mathrm{~L}$ of $\mathrm{CO}_{2}$, the intensity of both peaks increased and reached saturation without an observable binding energy shift. At the same time, the Fermi edge disappeared, indicating that the anionic electrons were consumed in reactions with adsorbed $\mathrm{CO}_{2}$.

The X-ray photoelectron spectroscopy (XPS) C $1 s$ spectra, together with the calculated $\mathrm{C} 1 \mathrm{~s}$ energy levels for physisorbed $\mathrm{CO}_{2}$, bent $\mathrm{CO}_{2}^{\delta-}$, tridentate $\mathrm{CO}_{2}$, chemisorbed and physisorbed $\mathrm{CO}$ and bidentate $\mathrm{CO}$, are presented in Fig. 5b. The XPS spectra show three distinct peaks at binding energies of 286, 289 and $292 \mathrm{eV}$. The peak at $289 \mathrm{eV}$ is broader than those at 286 and $292 \mathrm{eV}$. The ratio of these peak areas is about 4:4:1. The intensity of these signals correlates well with the $\mathrm{CO}_{2}$ dosage, which strongly suggests that the signal is derived from adsorbed $\mathrm{CO}_{2}$. The peaks at 286 and $289 \mathrm{eV}$ are apparent after $1 \mathrm{~L}$ of $\mathrm{CO}_{2}$ exposure and increases in magnitude at higher doses; these peaks do not disappear until the sample temperature is raised $>1,273 \mathrm{~K}$. This behaviour is similar to that observed for the $1,200-1,280 \mathrm{~cm}^{-1}$ FTIR band, which was associated with both the tridentate $\mathrm{CO}_{2}$ and bidentate $\mathrm{CO}$ configurations. Taking into account the TPD and FTIR data, comparison of the XPS spectrum and the calculated $\mathrm{C} 1 \mathrm{~s}$ energies (Fig. 5b) allows us to make the following assignments: the peak at $\sim 286 \mathrm{eV}$ is attributed to bidentate CO; the peak at $\sim 289 \mathrm{eV}$-to the tridentate (multidentate) $\mathrm{CO}_{2}$ configurations; and the peak at $\sim 292 \mathrm{eV}$ - to physisorbed $\mathrm{CO}_{2}$. Our calculations also show that the bent $\mathrm{CO}_{2}^{\delta-}$, chemisorbed and physisorbed $\mathrm{CO}$ can also 
a

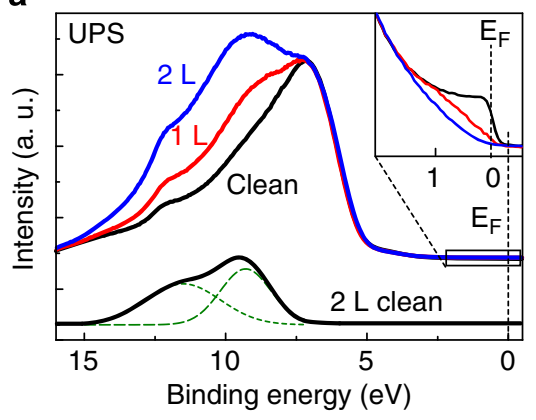

C

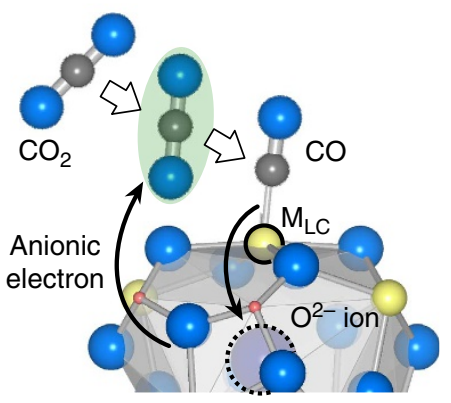

b

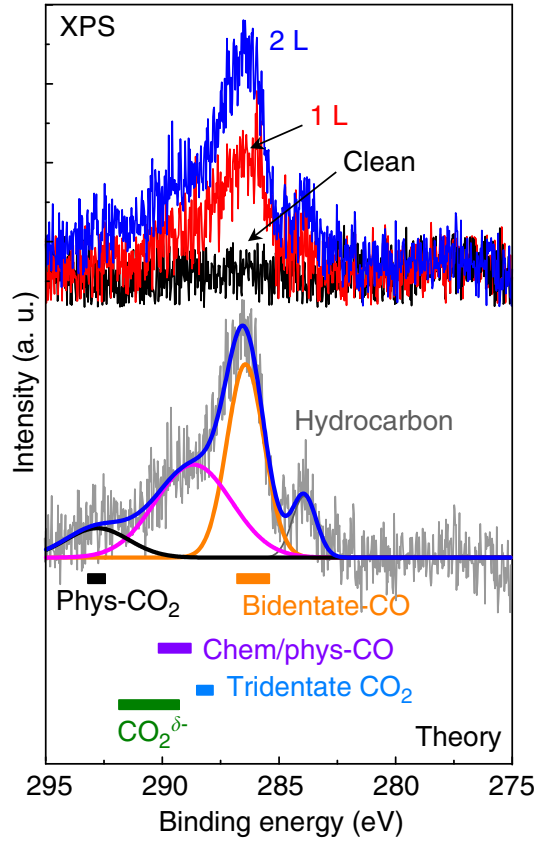

Figure 5 | PES spectra. UPS ( $\mathrm{He} \mathrm{I}$ ) (a) and XPS (b) spectra of the C12A7: $e^{-}$surface after various (clean, 1 and $2 \mathrm{~L}$ ) exposures to $\mathrm{CO} 2$ at RT. Inset in a shows magnification of the spectra. Bottom of $\mathbf{b}$ shows $\mathrm{C} 1 \mathrm{~s}$ energy level of possible surface species: physisorbed $\mathrm{CO}_{2}(\mathrm{phys}-\mathrm{CO})$, bent $\mathrm{CO}_{2}^{\delta-}$, dissociated (two types) and tridentate $\mathrm{CO}_{2}$ derived from calculation. Considering the FTIR results, the XPS signal could be assigned to bidentate CO (orange), phys $-\mathrm{CO}_{2}$ (black), tridentate and possibly chemisorbed (chem) and phys-CO (pink) and hydrocarbon contaminants (grey). (c) Schematic illustration of dissociation of $\mathrm{CO}_{2}$ (reaction (1)). The green-shaded spheres indicate transferred electronic charge from anionic electron to $\mathrm{CO}_{2}$.

contribute to the $289 \mathrm{eV}$ peak. The broadening of the $\sim 289 \mathrm{eV}$ peak is attributed to non-equivalent broken surface cages that result in various multidentate $\mathrm{CO}_{2}$ configurations and, possibly, chemisorbed and physisorbed $\mathrm{CO}$.

Subsurface extra-framework species. The subsurface region of the C12A7 framework manifests itself in two aspects. First, earlier studies have shown that $\mathrm{O}^{2-}$ ions occupying extra-framework sites in the near-surface cages can be more stable than those occupying LC surface sites ${ }^{28}$. Taking into account that C12A7 is a fast conductor of oxide ions ${ }^{25-27}$, this suggests that $\mathrm{O}^{2-}$ formed in reaction (1) can diffuse into the bulk C12A7: $e^{-}$, thus, making the original surface site available for a new reaction. Second, CO molecules are stabilized in the framework cages by either trapping two electrons or reacting with an extra-framework $\mathrm{O}^{2-}$ species with binding energies of 1.35 and $1.50 \mathrm{eV}$, respectively. The resulting structures and geometrical parameters (shown in Supplementary Fig. S3) are surprisingly similar to those for the surface bidentate $\mathrm{CO}$ and tridentate $\mathrm{CO}_{2}$; hence, we extend the use of these terms to the bulk species. Moreover, the calculated vibrational frequencies are $1,251 \mathrm{~cm}^{-1}$ for the bidentate $\mathrm{CO}$ and 1,244 and $1,316 \mathrm{~cm}^{-1}$ for the tridentate $\mathrm{CO}_{2}$, that is, in close agreement with the experimental data. Finally, the binding energy for the $\mathrm{C} 1 s$ level in the tridentate $\mathrm{CO}_{2}$ is $\sim 1.4 \mathrm{eV}$ smaller than that for the bidentate $\mathrm{CO}$, which is consistent with the assignments made for the surface species (Fig. 5). Thus, the spectroscopic characteristics of these subsurface CO-derived species are consistent with both IR and XPS measurements and $a b$ initio calculations.

\section{Discussion}

Table 1 summarizes the experimental observation of possible chemical species adsorbed on the C12A7: $e^{-}$surface. Our experiments and computational modelling complement each other and provide a consistent picture of $\mathrm{CO}_{2}$ interaction with the $\mathrm{C} 12 \mathrm{~A} 7: e^{-}$surface as follows. (1) The $\mathrm{C} 12 \mathrm{~A} 7: e^{-}$surfaces retain the basic features of the complex C12A7: $e^{-}$bulk structure: bulklike and broken cages. The cages are occupied by anionic electrons, which serve as anchors capable of trapping gas-phase molecules, such as $\mathrm{CO}$ and $\mathrm{CO}_{2}$. As the surface is corrugated and partially amorphous, configurations of adsorbed molecules are described by a distribution of binding energies rather than by a single value. (2) $\mathrm{CO}_{2}$ adsorption gives rise to five configuration types (Fig. 3): physisorbed $\mathrm{CO}_{2}$, bent $\mathrm{CO}_{2}^{\delta-}$, tridentate and dissociated $\mathrm{CO}+\mathrm{O}$, where $\mathrm{CO}$ is either in the bidentate or chemisorbed configurations. In addition, the $\mathrm{CO}$ can be stabilized in the subsurface region by interacting with extra-framework electrons and $\mathrm{O}^{2-}$ ions and by forming bidentate $\mathrm{CO}$ and tridentate $\mathrm{CO}_{2}$ in the bulk cages. The calculated activation energy for reaction (1) (see Fig. 5c) is $1-1.5 \mathrm{eV}$. (3) As the surface temperature increases, physisorbed $\mathrm{CO}_{2}$ and $\mathrm{CO}$ (bidentate or chemisorbed) become desorbed starting at 350 and $400 \mathrm{~K}$, respectively. We propose that at temperatures $>400 \mathrm{~K}$, some of the desorbed $\mathrm{CO}_{2}$ originates from the $\mathrm{CO}+\mathrm{O}$ recombination. At temperatures $>700 \mathrm{~K}$, this recombination is suppressed by faster atomic vibrations, and the $\mathrm{CO}_{2}$ desorption drops while $\mathrm{O}$-atom desorption appears. (4) At temperatures $>1,100 \mathrm{~K}$, all of the physisorbed $\mathrm{CO}_{2}$ and most of the $\mathrm{CO}$ have left the surface. However, decomposition of $\mathrm{CO}_{2}$ molecules at deep traps, such as tridentate configurations, becomes possible, which leads to a steep rise in desorption of both $\mathrm{CO}$ and $\mathrm{O}$ species.

In summary, we have demonstrated that $\mathrm{C} 12 \mathrm{~A} 7: e^{-}$surfaces can adsorb $\mathrm{CO}_{2}$ molecules and split them into $\mathrm{CO}$ molecules and $\mathrm{O}$ atoms at RT. According to the results of TPD measurements, molecular $\mathrm{CO}$ is the main desorption product. We propose that this desorption has a bimodal distribution. The CO molecules, formed at the surface due to $\mathrm{CO}_{2}$ decomposition at LC metal 
sites, desorb at $T>400 \mathrm{~K}$. At $T>1,100 \mathrm{~K}, \mathrm{CO}_{2}$ molecules adsorbed in the tridentate and similar configurations break up, thus forming another channel for desorption of $\mathrm{CO}$ and $\mathrm{O}$ species and replenishment of the sites available for $\mathrm{CO}_{2}$ chemisorption and splitting. As the mechanisms for the processes proposed here require no highly reactive species, such as metallic alkali or alkaline earth metals, nor high- and/or low-temperature conditions, $\mathrm{C} 12 \mathrm{~A} 7: e^{-}$is promising for practical applications in $\mathrm{CO}_{2}$ activation and splitting. This work provides a foundation for further research that is necessary to enable $\mathrm{C} 12 \mathrm{~A} 7: e^{-}$to function as a $\mathrm{CO}_{2}$-decomposition catalyst.

\section{Methods}

Sample preparation. We prepared the C12A7: $e^{-}$surface samples as follows. A 1-inch $\left[\mathrm{Ca}_{24} \mathrm{Al}_{28} \mathrm{O}_{64}\right]^{4+}\left(\mathrm{O}^{2-}\right)_{2}\left(\mathrm{C} 12 \mathrm{~A} 7: \mathrm{O}^{2-}\right)$ (refs 29-31) ingot was grown by the Czochralski method and sliced along (110) planes into single-crystal $3 \times 13 \times 1 \mathrm{~mm}^{3}$ wafers $^{32}$. The extra-framework oxygen ions were replaced with anionic electrons by heating the wafers at $1,373 \mathrm{~K}$ for $24 \mathrm{~h}$ under a titanium vapour atmosphere in an evacuated $\left(\sim 10^{-1} \mathrm{~Pa}\right)$ silica glass tube. The concentration of anionic electrons $\left(2 \times 10^{21} \mathrm{~cm}^{-3}\right)$, as determined from the optical absorption intensity at $2.8 \mathrm{eV}$, indicated that all of the extra-framework oxygen ions were removed in this process ${ }^{33}$. The samples were mirror polished mechanically with oil-based diamond powder slurries (9, 3 and $1 \mu \mathrm{m}$ particle sizes) and alumina powder slurry ( $50 \mathrm{~nm}$ particle size).

The C12A7: $e^{-}$surface samples were then transferred to an ultrahigh vacuum (UHV) apparatus with a base pressure of under $3 \times 10^{-8} \mathrm{~Pa}$ and cleaned using $\mathrm{Ar}^{+}$ion sputtering ( $5 \mathrm{keV}, 4.8 \mathrm{nA} \mathrm{cm}{ }^{-2}$ from the $45^{\circ}$ off-normal direction) followed by resistive heating at $1,273 \mathrm{~K}$ for $10 \mathrm{~min}$. This treatment is necessary to obtain a C12A7: $e^{-}$surface that retains the bulk cage structure, exhibits metallic conductivity and has a low work function ${ }^{22}$. After cooling to RT, the clean surface and electronic structure were examined using in situ XPS (Mg K $\alpha$ ) and UPS ( $\mathrm{He}$ I). Exposure of the samples to $\mathrm{CO}_{2}\left(99.999 \%\right.$ purity) $\left(\mathrm{C}^{18} \mathrm{O}_{2}\right.$ in the TPDs) was carried out by backfilling in the UHV apparatus through a variable leak valve. The gas line was evacuated and heated to ensure that the specimens remained clean. The injection port for the $\mathrm{CO}_{2}$ had a 1-mm opening size inside the apparatus and was located $5 \mathrm{~mm}$ away from the samples. A quadrupole mass spectrometer (ULVAC; MSQ-400) was used to monitor the partial pressure of the injection gas during exposure. The exposure was measured in units of Langmuirs ( $\mathrm{L}$ : $1.33 \times 10^{-4} \mathrm{Pas}$.)

After the samples were exposed to $\mathrm{CO}_{2}$ gas, the UHV chamber was evacuated immediately to a $3 \times 10^{-8} \mathrm{~Pa}$ base pressure before performing in situ TPD, PES (XPS and UPS) and FTIR-RAS measurements.

Temperature-programmed desorption. TPD spectra were taken in the 300 $1,273 \mathrm{~K}$ temperature range at a constant heating rate of $0.5 \mathrm{~K} \mathrm{~s}^{-1}$ using an SQ- 400 . The sample temperature was controlled via resistive heating with a homemade computer-controlled power supply. The upper limit of the sample temperature was determined by reference to the melting point of the sample ${ }^{34,35}$. The conditions required to achieve saturation of $\mathrm{CO}_{2}$ adsorption on $\mathrm{C} 12 \mathrm{~A} 7: e^{-}$were determined by monitoring the pressure level in the UHV apparatus during the TPD measurements and the TPD yield as a function of $\mathrm{CO}_{2}$ exposure.

Photoelectron spectroscopy. PES measurements were performed using a hemispherical analyser (Omicron) with a commercial non-monochromatic ultraviolet photon source (He I line: $h v=21.2 \mathrm{eV}, \Delta E=0.1 \mathrm{eV})$ and an X-ray source $(\mathrm{Mg} \mathrm{K} \alpha$ line: $h v=1,253.6 \mathrm{eV}, \Delta E=1.0 \mathrm{eV}$ ). During UPS measurements, the He I beam strikes the sample surface at an angle of $45^{\circ}$ to the surface normal and illuminates a spot approximately $2 \mathrm{~mm}$ in diameter. In XPS, X-ray photons hit the surface at an angle of $60^{\circ}$ to the surface normal, illuminating a spot several millimetres in diameter. All PES spectra were taken at RT and displayed as a function of the electron-binding energy with respect to the Fermi level.

\section{Fourier transform infrared reflection absorption spectroscopy. FTIR-RAS} spectra were taken at RT with an FTIR spectrometer (Bruker; Tensor 27). The infrared source and infrared detector were placed on the outside of the UHV apparatus. The spectra were obtained as a ratio of the single-beam spectra with the $\mathrm{CO}_{2}$ adsorbate and with the clean surface of the C12A7: $e^{-}$. All spectra comprised 256 scans taken at a $4-\mathrm{cm}^{-1}$ spectral resolution. The infrared light beam, extracted from the spectrometer, struck the sample surface at an angle of $85^{\circ}$ to the surface normal through a $\mathrm{CaF}_{2}$ window. After reflection of the light from the sample surface, it passed through an exit $\mathrm{CaF}_{2}$ window and was collected and focused onto a mercury cadmium telluride infrared detector cooled using liquid nitrogen. All optical paths were isolated from ambient air and were filled with dry nitrogen.

Theory. Computational modelling was carried out using density functional theory, with the generalized gradient approximation functional of $\mathrm{PBE}^{36}$, unless stated otherwise, and the projected augmented waves method ${ }^{37}$ implemented in the Vienna $a b$ initio simulation package ${ }^{38}$. The plane-wave basis set cutoff was set to $500 \mathrm{eV}$. The C12A7: $e^{-}$surface was modelled using a quasi-two-dimensional slab, in which one of the near-surface cages hosts two electrons, as described in detail elsewhere ${ }^{28}$. The surfaces exhibit a large number of structurally similar but not identical surface sites, including $\mathrm{LC} \mathrm{Ca}^{2+}$ and $\mathrm{Al}^{3+}$ sites. The super-cell parameters in the $x-y$ plane and in the direction perpendicular to the surface were fixed at 12 and $24 \AA$, respectively. As the near-surface region is partially disordered $^{38}$, the calculations were carried out for the $\Gamma$ point of the Brillouin zone only. Activation energies for the $\mathrm{CO}_{2}$-decomposition process were calculated using the nudged elastic band method and eight images. The infrared intensities for individual $\mathrm{CO}_{x}$ species were calculated with respect to a common reference. The dispersion correction was calculated using a previously implemented method ${ }^{24}$. The configuration pre-optimized using the PBE functional was used to calculate the adsorption energies (reported for the chemisorbed configurations alongside the PBE results), the C $1 s$ core levels with the hybrid density functional B3LYP ${ }^{39,40}$, the CRYSTAL09 package ${ }^{41}$ and all electron Gaussian-type contracted basis sets for Ca $(5 s, 4 p, 1 d), \mathrm{Al}(4 s, 3 p, 1 d), \mathrm{O}(4 s, 3 p, 1 d)$ and $\mathrm{C}(9 s, 3 p, 2 d)$ http://www.crystal.unito.it/ Basis_Sets/Ptable.html. The reasons for using the B3LYP density functionals and the correlation of the corresponding adsorption energies are presented in the Supplementary Fig. S4.

\section{References}

1. Lackner, K. S. A guide to $\mathrm{CO}_{2}$ sequestration. Science 300, 1677-1678 (2003).

2. D’Alessandro, D. M., Smit, B. \& Long, J. R. Carbon dioxide capture: Prospects for new materials. Angew. Chem Int. Ed. 49, 6058-6082 (2010).

3. Freund, H. J. \& Roberts, M. W. Surface chemistry of carbon dioxide. Surf. Sci. Rep. 25, 225-273 (1996).

4. Fukuda, Y. \& Tanabe, K. Infrared study of carbon dioxide adsorbed on magnesium and calcium oxide. Bull. Chem. Soc. Jpn 88, 1616-1619 (1973).

5. Busca, G. \& Lorenzelli, V. Infrared spectroscopic identification of species arising from reactive adsorption of carbon oxide on metal oxide surfaces. Mater. Chem. 7, 89-126 (1982).

6. Fukuda, Y. \& Toyoshima, I. AES and UPS studies of $\mathrm{CO}$ and $\mathrm{CO}_{2}$ adsorption on $\mathrm{Mg}$ and MgO. Surf. Sci. 158, 482-489 (1985).

7. Au, C. T., Hirsch, W. \& Hirschwald, W. Adsorption and interaction of carbon dioxide, formic acid and hydrogen/carbondioxide mixtures on (10-10) zinc oxide surface studied by photoelectron spectroscopy (XPS and UPS). Surf. Sci. 199, 507-517 (1988).

8. Tsami, A., Grillo, F., Bowker, M. \& Nix, R. M. Model NSR catalysts: fabrication and reactivity of barium oxide layers on $\mathrm{Cu}(111)$. Surf. Sci. 600, 3403-3418 (2006).

9. Dutta, G., Sokol, A. A., Catlow, C. R. A., Keal, T. W. \& Sherwood, P. Activation of carbon dioxide over zinc oxide by localised electrons. ChemPhysChem 13, 3453-3456 (2012).

10. Copperthwaite, R. G., Davies, P. R., Morris, M. A., Roberts, M. W. \& Ryder, R. A. The reactive chemisorption of carbon dioxide at magnesium and copper surfaces at low temperature. Catal. Lett. 1, 11-19 (1988).

11. Berko, A. \& Solymosi, F. Effects of potassium on the chemisorption of $\mathrm{CO}_{2}$ and CO on the Pd(100) surface. Surf. Sci. 171, L498-L502 (1986).

12. Kiss, J., Revesz, K. \& Solymosi, F. Photoelectron spectroscopic studies of the adsorption of $\mathrm{CO}_{2}$ on potassium-promoted Rh(111) surface. Surf. Sci. 207, 36-54 (1988)

13. Liu, Z. M., Zhou, Y., Solymosi, F. \& White, J. M. Spectroscopic study of K-induced activation of $\mathrm{CO}_{2}$ on $\mathrm{Pt}(111)$. Surf. Sci. 245, 289-304 (1991).

14. Matsuishi, S. et al. High-density electron anions in a nanoporous single crystal: $\left[\mathrm{Ca}_{24} \mathrm{Al}_{28} \mathrm{O}_{64}\right]^{4+}\left(4 \mathrm{e}^{-}\right)$. Science 301, 626-629 (2003).

15. Kim, S. W. et al. Metallic state in a lime-alumina compound with nanoporous structure. Nano Lett. 7, 1138-1143 (2005).

16. Sushko, P. V., Shluger, A. L., Hirano, M. \& Hosono, H. From insulator to electride: a theoretical model of nanoporous oxide $12 \mathrm{CaO} \cdot 7 \mathrm{Al}_{2} \mathrm{O}_{3} . J . A m$. Chem. Soc. 129, 942-951 (2007).

17. Dye, J. L. Progress in Inorganic Chemistry (32) 327-441 (Wiley, 1984).

18. Dye, J. L. Electrides-ionic salts with electrons as the anions. Science 247, 663-668 (1990).

19. Dye, J. L. Ionic salts with electrons as the anions. Science 301, 607-608 (2003).

20. Toda, Y. et al. Work function of a room-temperature stable electride $\left[\mathrm{Ca}_{24} \mathrm{Al}_{28} \mathrm{O}_{64}\right]^{4+}\left(e^{-}\right)_{4}$. Adv. Mater. 19, 3564-3569 (2007).

21. Carley, A. F., Davies, P. R., Moser, E. M. \& Roberts, M. W. Facile hydrogenation of carbon dioxide at $\mathrm{Al}(111)$ surfaces: the role of coadsorbed water. Surf. Sci. 364, L563-L567 (1996).

22. Toda, Y., Kubota, Y., Hirano, M., Hirayama, H. \& Hosono, H. Surface of roomtemperature-stable electride $\left[\mathrm{Ca}_{24} \mathrm{Al}_{28} \mathrm{O}_{64}\right]^{4+}\left(e^{-}\right)_{4}$ : preparation and its characterization by atomic-resolution scanning tunneling microscopy. ACS Nano 5, 1907-1914 (2011).

23. Pan, Y., Liu, C., Wiltowski, T. S. \& Ge, Q. $\mathrm{CO}_{2}$ adsorption and activation over $\gamma-\mathrm{Al}_{2} \mathrm{O}_{3}$-supported transition metal dimers: A density functional study. Catal. Today 147, 68-76 (2009). 
24. Klimes, J., Bowler, D. R. \& Michaelides, A. Van der Waals density functionals applied to solids. Phys. Rev. B 83, 195131 (2011).

25. Lacerda, M., Irvine, J. T. S., Glasser, F. P. \& West, A. R. High oxide ion conductivity in $\mathrm{Ca}_{12} \mathrm{Al}_{14} \mathrm{O}_{33}$. Nature 332, 525-526 (1988).

26. Sushko, P. V., Shluger, A. L., Hayashi, K., Hirano, M. \& Hosono, H. Mechanisms of oxygen ion diffusion in a nanoporous complex oxide $12 \mathrm{CaO} \cdot 7 \mathrm{Al}_{2} \mathrm{O}_{3}$. Phys. Rev. B 73, 014101 (2006).

27. Hayashi, K., Matsuishi, S., Hirano, M. \& Hosono, H. Formation of oxygen radicals in $12 \mathrm{CaO} \cdot 7 \mathrm{Al}_{2} \mathrm{O}_{3}$ : instability of extraframework oxide ions and uptake of oxygen gas. J. Phys. Chem. B 108, 8920-8925 (2004).

28. Sushko, P. V., Shluger, A. L., Toda, Y., Hirano, M. \& Hosono, H. Models of stoichiometric and oxygen deficient surfaces subnanoporous $12 \mathrm{CaO} \cdot 7 \mathrm{Al}_{2} \mathrm{O}_{3}$. Proc. R. Soc. A 467, 2066-2083 (2011).

29. Bartl, H. \& Scheller, T. Zur Struktur des $12 \mathrm{CaO} \cdot 7 \mathrm{Al}_{2} \mathrm{O}_{3}$. Neues Jahrb. Mineral. Monatsh. 35, 547-552 (1970).

30. Chatterjee, A. K. \& Zhmoidin, G. I. Phase equilibrium diagram of system CaO$\mathrm{Al}_{2} \mathrm{O}_{3}-\mathrm{CaF}_{2}$. J. Mater. Sci. 7, 93-97 (1972).

31. Taylor, H. F. W. Cement Chemistry 2nd edn (Thomas Telford, 1997).

32. Kurashige, K. et al. Czochralski growth of $12 \mathrm{CaO} \cdot 7 \mathrm{Al}_{2} \mathrm{O}_{3}$ crystals. Cryst. Growth Design 6, 1602-1605 (2006).

33. Matsuishi, S., Kim, S. W., Kamiya, T., Hirano, M. \& Hosono, H. Localized and delocalized electrons in room-temperature stable electride $\left[\mathrm{Ca}_{24} \mathrm{Al}_{28} \mathrm{O}_{64}\right]^{4+}$ $\left(\mathrm{O}^{2-}\right)_{2-\mathrm{x}}\left(e^{-}\right)_{2 \mathrm{x}}$ : analysis of optical reflectance spectra. J. Phys. Chem. C 112, 4753-4760 (2008).

34. Kim, S. W. et al. Simple and efficient fabrication of room temperature stable electride: melt-solidification and glass ceramics. J. Am. Chem. Soc. 127, 1370-1371 (2005).

35. Kim, S. W., Shimoyama, T. \& Hosono, H. Solvated electrons in hightemperature melts and glasses of the room-temperature stable electride $\left[\mathrm{Ca}_{24} \mathrm{Al}_{28} \mathrm{O}_{64}\right]^{4+} .4 \mathrm{e}^{-}$. Science 333, 71-74 (2011).

36. Perdew, J. P., Burke, K. \& Ernzerhof, M. Generalized gradient approximation made simple. Phys. Rev. Lett. 77, 3865-3868 (1996).

37. Blöchl, P. E. Projector augmented-wave method. Phys. Rev. B 50, 17953-17979 (1994).

38. Kresse, G. \& Joubert, D. From ultrasoft pseudopotentials to the projector augmented-wave method. Phys. Rev. B 59, 1758-1775 (1999).

39. Becke, A. D. Density-functional thermochemistry. III. The role of exact exchange. J. Chem. Phys. 98, 5648-5652 (1993).
40. Lee, C., Yang, W. \& Parr, R. G. Development of the Colle-Salvetti correlation-energy formula into a functional of the electron density. Phys. Rev. B 37, 785-789 (1988). 41. Dovesi, R. et al. CRYSTAL09 User's Manual (University of Torino, 2009).

\section{Acknowledgements}

We thank Alexander Shluger and Nikolai Petrik for stimulating discussions. This study was supported by the Funding Program for World-Leading Innovative R\&D on Science and Technology (FIRST), Japan Society for the Promotion of Science, Japan. A part of this study was supported by the MEXT Element Strategy Initiative. P.V.S. is supported by the Royal Society. Computational resources in the Environmental Molecular Sciences Laboratory, located at Pacific Northwest National Laboratory, and the HECToR facility available via UK's HPC Materials Chemistry Consortium funded by EPSRC (EP/ F067496) are gratefully acknowledged.

\section{Author contributions}

Y.T. and H.H. designed and performed the experiments. A.T., N.K. and P.V.S. designed and performed the theoretical calculations. Y.T., P.V.S. and H.H. co-wrote the manuscript. All authors discussed the manuscript. H.H. envisaged and supervised the entire project.

\section{Additional information}

Supplementary Information accompanies this paper at http://www.nature.com/ naturecommunications

Competing financial interests: The authors declare no competing financial interests.

Reprints and permission information is available online at http://npg.nature.com/ reprintsandpermissions/

How to cite this article: Toda, Y. et al. Activation and splitting of carbon dioxide on the surface of an inorganic electride material. Nat. Commun. 4:2378 doi: 10.1038/ ncomms3378 (2013).

(c) (i) $\ominus$ This work is licensed under a Creative Commons AttributionNonCommercial-NoDerivs 3.0 Unported License. To view a copy of this license, visit http://creativecommons.org/licenses/by-nc-nd/3.0/ 